\title{
XANTHOGRANULOMATOUS CHOLECYSTITIS - DIAGNOSTIC PARODY AND SURGICAL MALADY
}

\author{
Darwin Britto Devadhason ${ }^{1}$, Alankrith Ramesh Kashyap², Soundrapandian Floret ${ }^{3}$, Jaison Jacob John4, Balasundararajan Uma ${ }^{5}$
}

${ }^{1}$ Assistant Professor, Department of General Surgery, SRM Medical College, Hospital and Research Centre, Chennai.

2Postgraduate, Department of General Surgery, SRM Medical College, Hospital and Research Centre, Chennai.

3 Professor, Department of General Surgery, SRM Medical College, Hospital and Research Centre, Chennai.

4 Professor, Department of Pathology, SRM Medical College, Hospital and Research Centre, Chennai.

5Postgraduate, Department of Pathology, SRM Medical College, Hospital and Research Centre, Chennai.

\section{BACKGROUND}

\section{ABSTRACT}

Xanthogranulomatous cholecystitis is a form of chronic cholecystitis which is rarely encountered in surgical practice and it presents as puzzle to the clinician and the radiologist. During surgery, it shows properties like severe adhesion and infiltration masquerading cancer, thus adequate knowledge about this entity can be useful in prevention long-term morbidity which is associated with it. We present a case of xanthogranulomatous cholecystitis in a 45-year-old male patient, who underwent a difficult but complete cholecystectomy and made an uneventful postoperative recovery.

\section{KEYWORDS}

Xanthogranulomatous Cholecystitis.

HOW TO CITE THIS ARTICLE: Devadhason DB, Kashyap AR, Floret S, et al. Xanthogranulomatous cholecystitis - diagnostic parody and surgical malady. J. Evolution Med. Dent. Sci. 2016;5(87):6516-6518, DOI: 10.14260/jemds/2016/1472

\section{BACKGROUND}

Xanthogranulomatous cholecystitis is an atypical form of chronic cholecystitis characterised by infiltration of plasma cells, lipid laden histiocytes, proliferation of fibroblasts in the gall bladder wall.[1] Due to the rupture of the serosa, infiltration and adhesion to the surrounding tissues occur.[1] Though a benign rare disease, it mimics many other forms of cholecystitis and also gall bladder carcinoma which poses a dilemma to the diagnostician and radiologist and cumbersome to the surgeon. $[1,2,3]$ It is associated with post-operative morbidity and prolonged hospital stay.[1]

\section{CASE REPORT}

A 45-year-old male presented with complaints in the upper abdomen, more towards right side since 6 months. The pain was intermittent, non-radiating associated with occasional vomiting of food contents. One episode of fever 1 week back, low grade and subsided on medication. There was a history of jaundice. Similar episodes in the past 1 year - symptomatically managed. Patient passed dark coloured urine. No bowel disturbances. Patient consumed alcohol for 10 years, last binge 1 week before admission date. Not a smoker or tobacco abuse. On examination, patient did not have pallor, but had marked icterus. Vitals recorded were stable. Blood investigations: Total Count raised: 12200 cells/cu.mm (Normal 4000-11000 cells/cu.mm).

Total Cholesterol: $150 \mathrm{mg} / \mathrm{dL}$ (Normal < $200 \mathrm{mg} / \mathrm{dL}$ ); LDL: $80 \mathrm{mg} / \mathrm{dL}$ (Normal < $100 \mathrm{mg} / \mathrm{dL}$ ); HDL: $45 \mathrm{mg} / \mathrm{dL}$ (Normal 40$60 \mathrm{mg} / \mathrm{dL}$ ) were within normal limits.

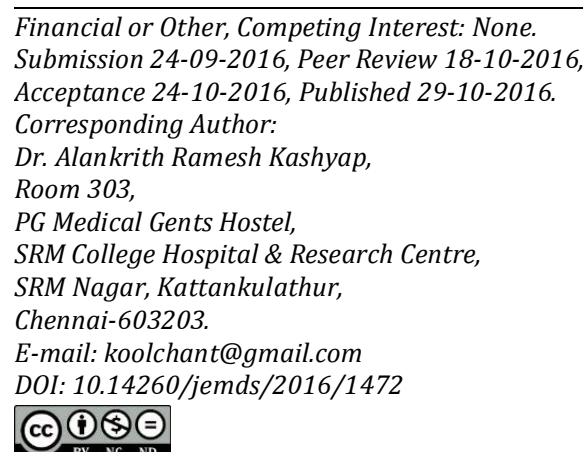

\section{Liver Function Tests}

Total Bilirubin: $3 \mathrm{mg} / \mathrm{dL}$ (Normal $0.2-1 \mathrm{mg} / \mathrm{dL}$ ). Indirect Bilirubin: $0.6 \mathrm{mg} / \mathrm{dL}$ (Normal $<0.8 \mathrm{mg} / \mathrm{dL}$ ). Direct Bilirubin: $2.4 \mathrm{mg} / \mathrm{dL}$ (Normal $<0.1 \mathrm{mg} / \mathrm{dL}$ ).

Total Protein: $7 \mathrm{~g} / \mathrm{dL}$ (Normal 6-8 g/dL). Albumin: $4.5 \mathrm{~g} / \mathrm{dL}$ (Normal $3.5-5 \mathrm{~g} / \mathrm{dL}$ ).

AST: 20 IU/L (Normal 10-40 IU/L).

ALT: 25 IU/L (Normal 10-40 IU/L).

Ultrasound (USG) and Computed Tomography (CT) Abdomen

Thickened and oedematous gall bladder wall, multiple gall bladder calculi and dilated Common Bile Duct (CBD) indicative of features of cholecystitis.

\section{Magnetic Resonance Cholangiopancreaticography (MRCP)}

Multiple gall bladder calculi including the neck and CBD dilated $\sim 11 \mathrm{~mm}$ with small calculi indicative of calculus, cholecystitis with choledocholithiasis.

Endoscopic Retrograde Cholangiopancreaticography (ERCP) was done under adequate anti-microbial cover; CBD calculi extraction followed by CBD stenting to relieve the obstruction.

Patient was observed for 2 weeks. His jaundice subsided with serum bilirubin returning to normal levels. After 1 month, he was planned for elective open cholecystectomy.

\section{Procedure Done}

Anterograde (Fundus down) open cholecystectomy.

\section{Intraoperative Findings}

Gallbladder thickened like a mass, densely adhered to omentum, transverse colon and duodenum. Calot's triangle was inflamed [Figure 1]. Pre-operative CBD stenting (via ERCP) proved a boon to distinguish between cystic duct and CBD (on table palpation of stent), thus avoiding subsequent injury to the same. 


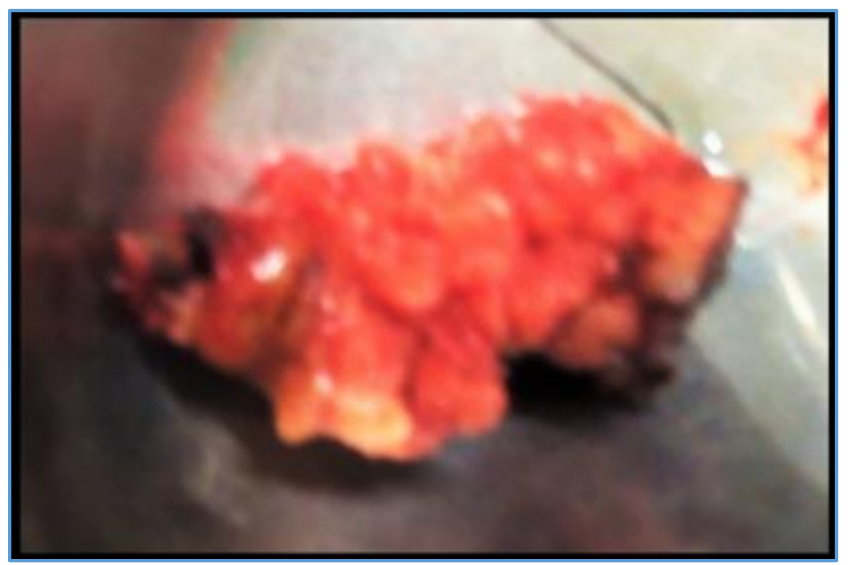

Figure 1. Gallbladder Densely Adhered to Omentum

Histopathology: Xanthogranulomatous cholecystitis [Figure 2].

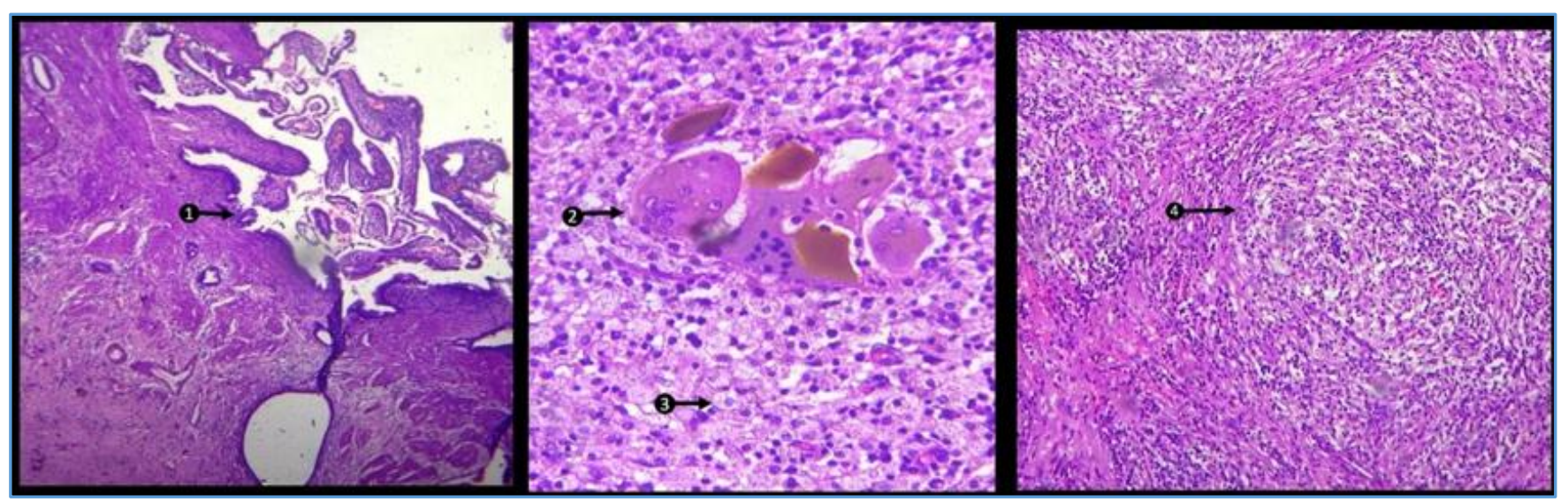

Figure 2. Mucosal Ulceration (1). Foreign Body Giant Cells, (2). Foamy Macrophages (3). Ill-Defined Granuloma with Foamy Macrophages (4)

\section{Post-Operative Course}

The sutured wound site became indurated and oedematous by the sixth post-operative day. Minimal serous collection could be exuded. After suture removal on the twelfth post-operative day, wound gaping and infection occurred. Daily dressing under anti-microbial coverage reduced the infection, which was followed by secondary suturing. Further course in hospital was uneventful and patient was discharged.

\section{DISCUSSION}

Xanthogranulomatous is an infrequent variant of chronic cholecystitis with reported literature incidence ranging from $0.7 \%-13.2 \%$ and in India to about $6 \% \cdot{ }^{[1,2]}$ It mostly affects women (Male-to-female ratio 1:9) during fifth to sixth decades.[1] It is mostly always linked with gallstones with pathogenesis being a mystery, trigger being gallstones, obstruction to bile flow and cholestasis and infection associated with ruptured Rokitansky-Aschoff sinuses (outpouchings of mucosal epithelium through gall bladder wall).[3,4] It starts as an inflammatory process and proceeds to a granulomatous reaction, the clinical features being right hypochondrium and epigastric pain, jaundice, vomiting and a high association with CBD stones and Mirizzi syndrome. ${ }^{[5,6]}$ Clinical examination may not be helpful to distinctly diagnose xanthogranulomatous cholecystitis, though a history of similar episodes in the past can be elicited thus making it difficult to differentiate from other inflammatory gall bladder diseases and cholelithiasis..[3,7]
Ultrasonogram of the abdomen and CT reveal only gallbladder thickening and presence of gallstones, which are congruous to any form of cholecystitis - thus making the preoperative diagnosis obscure.[6,7] B-mode ultrasound can sometimes help in diagnosis of xanthogranulomatous cholecystitis if the features like hypoechoic intraluminal nodules with hyperechoic thickened gallbladder wall are seen, but these often get missed owing to rarity in incidence and scarcity of knowledge about this disease, thus warranting the need to confirm the diagnosis on histopathological grounds.[5,6] MRCP and ERCP can not only diagnose the anatomy of the biliary tree, but also relieve the obstruction and obtain biopsy.[5] Nevertheless, open cholecystectomy remains the main modality of treatment, though the dissection can be technically irksome due to gallbladder being thickened along with infiltration into the liver parenchyma and adhesions to transverse colon, duodenum - which may lead to a partial cholecystectomy so as to avoid injury to the CBD; an injury that can be prevented by a pre-operative stenting or intraoperative CBD exploration.[1,5,6] Owing to the potential of infiltration and dense adhesions, it mimics carcinoma of gallbladder macroscopically.[1,6] Histopathology confirms the diagnosis, yet scenario may sometimes get convoluted microscopically - marked by chronic inflammation, necrosis, haemorrhage, infiltration into serosa, foamy macrophages, spindle-shaped xanthoma cells in storiform pattern and exuberant fibrosis. $[1,4,6,7]$ 
Associated ramifications can range from post-operative wound infection, abscess, enterobiliary fistulae formation, bile leak to bile peritonitis, pleural effusion and hepatorenal failure.[1,7]

\section{CONCLUSION}

Significance of xanthogranulomatous cholecystitis: 1) Rare occurrence, 2) Sparse knowledge about the disease, 3) Symptoms resembling common forms of chronic cholecystitis, 4) Onerous imaging need, 5) Operative perplexity, 6) Masquerades carcinoma macroscopically and microscopically, 7) Multiple post-operative complications and long-term morbidity. Xanthogranulomatous cholecystitis is an enthralling entity, a pre-operative conundrum to the clinician, diagnostic enigma to the radiologists, formidable challenge to the operating surgeons, ambiguous cryptogram to the reporting pathologist. Thus xanthogranulomatous presents a parody to the available knowledge about this disease and a malady not only to the distressed patient but also the operating surgeon. A better understanding in future may entail quicker clinical diagnosis, improved imaging accuracy and specificity, smoother operative proceeding for long-term benefit of the patient.

\section{REFERENCES}

1. Yildrim $\mathrm{M}$, Oztekin $\mathrm{O}$, Akdamar $\mathrm{F}$, et al. Xanthogranulomatous cholecystitis remains a challenge in medical practice: experience in 24 cases. Radiol Oncol 2009;43(2):76-83.

2. Yuman F. Hepatobiliary cancer. PMPH-USA 2013:63.

3. Odze RD, Goldblum JR. Surgical pathology of the GI tract, liver, biliary tract, and pancreas. Elsevier Health Sciences 2009:835.

4. Kumar V, Abbas AK, Fausto N. Robins and contran pathologic basis of disease. Philadelphia: Saunders 2004:933.

5. Spinelli A, Schumacher G, Pascher A, et al. Extended surgical resection for xanthogranulomatous cholecystitis mimicking advanced gallbladder carcinoma: a case report and review of literature. World J Gastroenterol 2006;12(14):2293-6.

6. Sheng-Hua H, Yan-Ling C. Diagnosis and treatment of xanthogranulomatous cholecystitis: a report of 39 cases. Cell Biochem Biophys 2012;64(2):131-5.

7. Roberts KM, Parsons MA. Xanthogranulomatous cholecystitis: clinicopathological study of 13 cases. J Clin Pathol 1987;40(4):412-7. 